\title{
Rachipagus parasitic twin in an Ethiopian neonate: A case report from the Horn of Africa
}

\author{
Daniel Zewdneh Solomon*, Natae Fekadu and Yocabel Gorfu \\ Department of Radiology, School of Medicine, College of Health Sciences, Addis Ababa University, Ethiopia.
}

Accepted 2 July, 2018

\begin{abstract}
Parasitic twining, also known as heteropagus is an asymmetric twinning of conjoined identical or monozygotic twins where the tissues of a severely defective twin (the parasite) are dependent on the cardiovascular system of the other twin (autosite) for survival. The condition only occurs when an undeveloped or underdeveloped twin is attached to parts of the body of the twin that develops and is delivered. The estimated incidence is approximately 1 per 1 million live births. To date, only a few isolated case reports are published in the literature of this rare congenital anomaly. Here, we report a case of this rare entity in a neonate referred to our teaching hospital.
\end{abstract}

Keywords: Parasite, twin, rachipagus.

${ }^{*}$ Corresponding author. E-mail: dzewdnehsolomon@yahoo.com.

\section{INTRODUCTION}

Heteropagus is a term used to describe the development of an asymmetrical form of conjoined twinning when one of the twins monopolizes the placental blood at the expense of the other fetus with consequent ischaemic atrophy of the latter. Rachipagus is to mean the fusion has occurred at the spinal level (Solak et al., 2012). It is a rare entity with an estimated incidence of less than 0.1 in 100,000 live births (Singh, 2012). There are very few case reports in the English literature.

The earliest documented scientific report was made by a French surgeon, Ambroise Pare in the $16^{\text {th }}$ century.Conjoined twins are an extremely rare and rather complexmal development of monozygotic twinning, and is associated with high perinatal mortality. The commonest defect of blastogenesis is monozygotic twinning resulting in conjoint twinsthe category of which includes internal, "endoparasitic," or fetus-in-fetu twins. This phenomenon only arises when the twinning event occurs at about the primitive streak stage of development, in about 13 to 14 days after fertilization, and is exclusively associated with monoamniotic monochorionic type.

Two contradicting theories exist to explain the origins ofconjoined twins. The older and most generally acceptedtheory is fission, in which the fertilized egg splits partially. The second theory is fusion, in which a fertilized eggcompletely separates, but stem cells (which search for similar cells) find like-stem cells on the other twin and fuse the twins together.

Surgery to separate conjoined twins may range from relatively simple to extremely complex, depending on the point of attachment and the internal parts that are shared. Imaging with ultrasound, angiography, CT or MRI is very essential for planning surgical separation (Aktar et al., 2012). Most of the cases reported and published are from developing countries. Prenatal sonography has also been reported in one publication where a pyopagustetrapus parasitic twin was identified followed by a successful excision of the parasite at 38 weeks of gestation (Aktar et al., 2012). Here, we report a case of this rare entity in a neonate referred to our teaching hospital.

\section{CASE REPORT}

This is a neonate born to a 30-year-old Para I lady who was referred to Tikur Anbessa hospital for lower lumbar mass on the $4^{\text {th }}$ day of the livery. The neonate was born to parents that do not belong to the same family tree. The mother had ANC follow-up during pregnancy, where she was screened for hepatitis B virus, HIV, syphilis infection 
that turned to be negative. The mother has received unspecified dosage of folate supplements and vaccination for tetanus. She had three sets of obstetric ultrasound scans in the third trimester, all were reported as normal. Over all the pregnancy was uneventful.

The delivery was via spontaneous vaginal delivery (SVD); it was uneventful, the neonate cried immediately. The Neonate was born on term when calculated from last menstrual period.

On physical examination, the vital signs and anthropometry was in the normal range. The pertinent finding was in the musculoskeletal system. There was a huge mass over the lower lumbar region with flocculent cystic component and a solid part with firm to hard consistency. The solid component is tubular with small firm nodules attached to the end. There was an associated hair tuff on the mass (Figure 1). The neonate cried when the mass was pinched and there was no motor weakness in the lower extremity.

The neonate was examined with ultrasound, computer tomography (CT) and magnetic resonant imaging (MRI). On ultrasound, the mass showed predominantly cystic component that contained anechoic fluid with no debris. The solid component has a well corticated bone with distal shadowing having no associated soft tissue. On MRI (Figure 2), spina bifida was demonstrated on L3 and L4 vertebrae with the dural sac of the neonate extending posteriorly through the defect to communicate with mass. There was an associated splitting of cord at L3 level with part of the cord also extending posteriorly to the mass. CT showed (Figures 3 and 4 ) the bony component of the mass to be rudimentary vertebral components.

Resection of the mass with repair was done; surgery was uneventful and the neonate was discharged on the $4^{\text {th }}$ post operation day.

\section{DISCUSSION}

The earliest description of heteropagus (parasitic) twining was perhaps in the $16^{\text {th }}$ century by a French surgeon Ambroise pare. As described by spencer the twins are conjoined where one of them (parasite) isseverely defective and depends on the other (autosite) for survival (Singh, 2012).

Classification of conjoined twins is based on the site of the union. The thoraco-omphalopagus are attached at the chest and abdomen, pygopagus are joined at the buttocks, ischiopagus are attached at ischion, and craniopagus at the level of the head. When the merger is on the spine it is rachipagus (Sanoussi et al., 2010).

Most authors mention a clear predominance of the male sex with about $78 \%$ being males. Until now, no particular risk factors for developing heteropagus twins have been reported (Aktar et al., 2012). However, a case report from Niger has identified consanguineous marriage in both cases of their case report (Sanoussi et al., 2010).

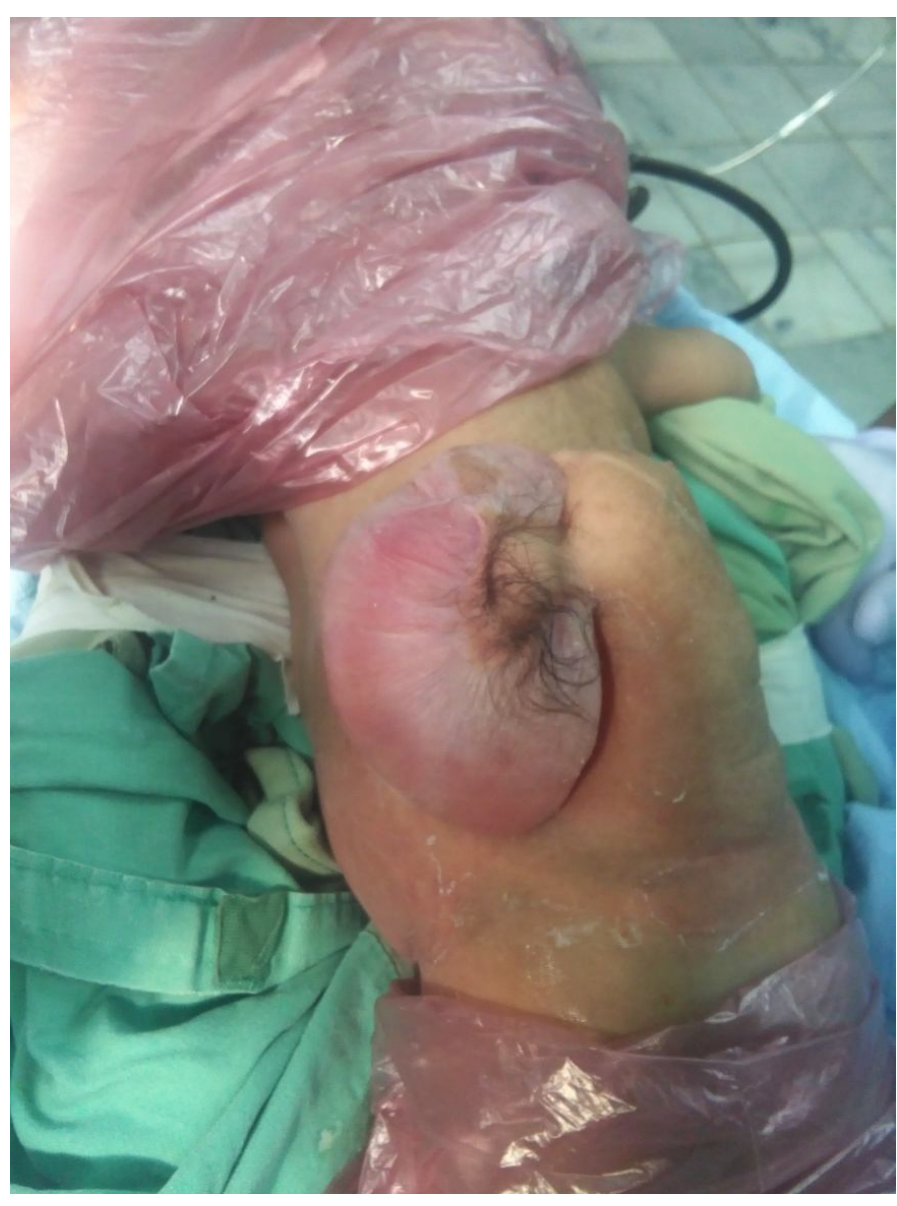

Figure 1. A mass located and arising from the lumbo-sacral area which had firm cystic and solid components on palpation. A tuft of hair could be seen on the surface as well.

The commonest variety mentioned in the literature is epigastric heteropagus which is also known as omphalopagus.

The cause of heteropagus twins is not fully clarified. One popular theory insinuates a concept of incomplete fission of one zygote occurring at about 14 days after fertilization (Fierling et al., 2015; Trainavicius et al., 2013). Others suggest the alternate hypothesis that heteropagus twins originate from the fusion of two separate zygotes at a later stage. Therefore, there are two conflicting theories (fission vs fusion) to date (Solak et al., 2012; Sanoussi et al., 2010; Aktar et al., 2012).

It is not uncommon to find sensory or motor innervations of the autosite (Sanoussi et al., 2010). In our case, we report that there was no spontaneous movement of the parasites, but the autosite was sensitive to painful parasite stimulation. The attachment of the parasite to the vertebrae could be at any level (Sanoussi et al., 2010). In our case, it was at mid lumbar region.

The neural tube defects associated with ectopic limbs have been reported in a few cases. Gopal et al. (2015) reported accessory legs associated with spina bifida and 


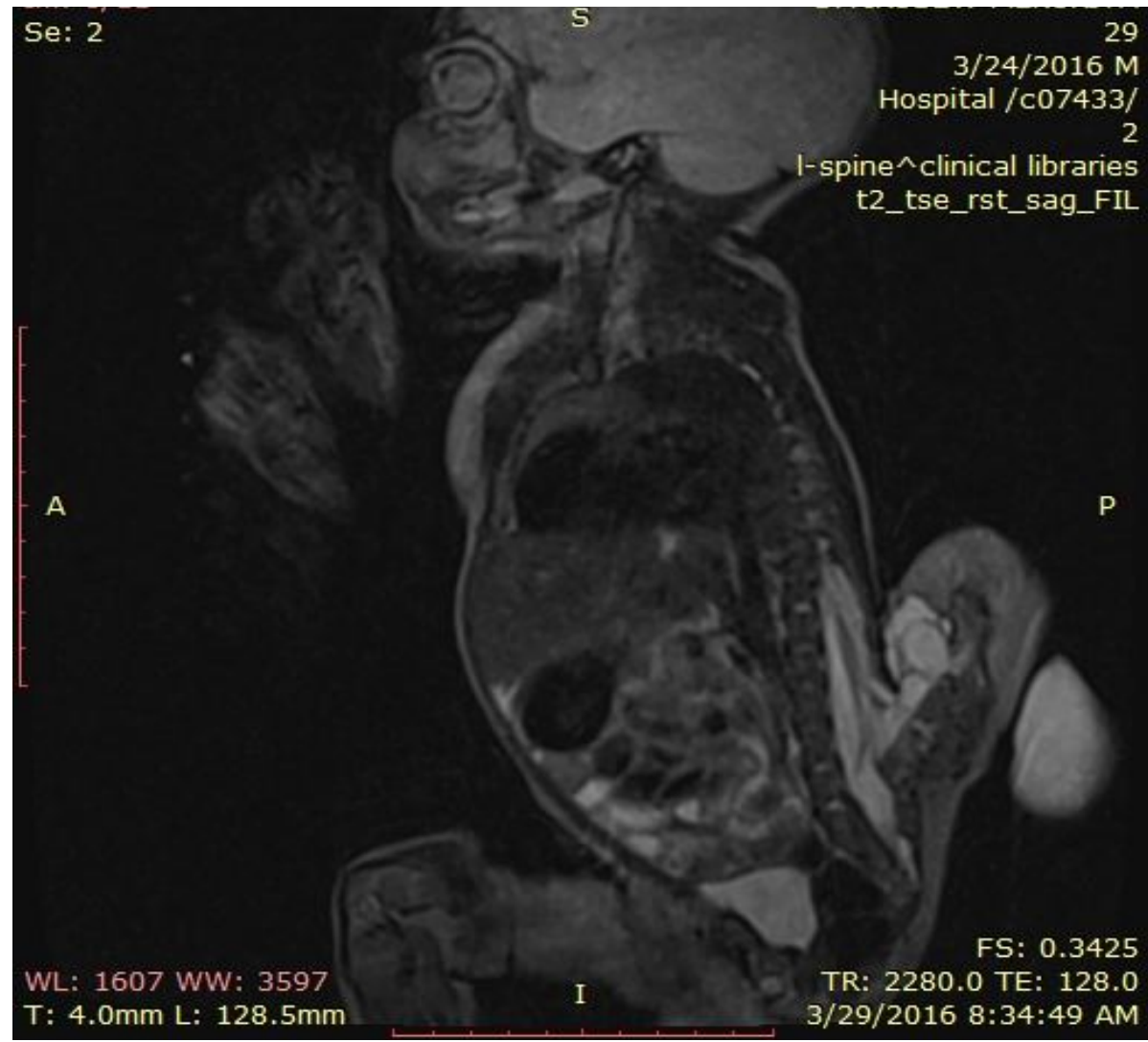

Figure 2. T2-Weighted MR image showed spina bifida at L3 and L4 vertebral levels with the dural sac of the neonate extending posteriorly through the defect to communicate with mass with splitting of the spinal cord at L3 level with part of the cord extending to the mass posteriorly.

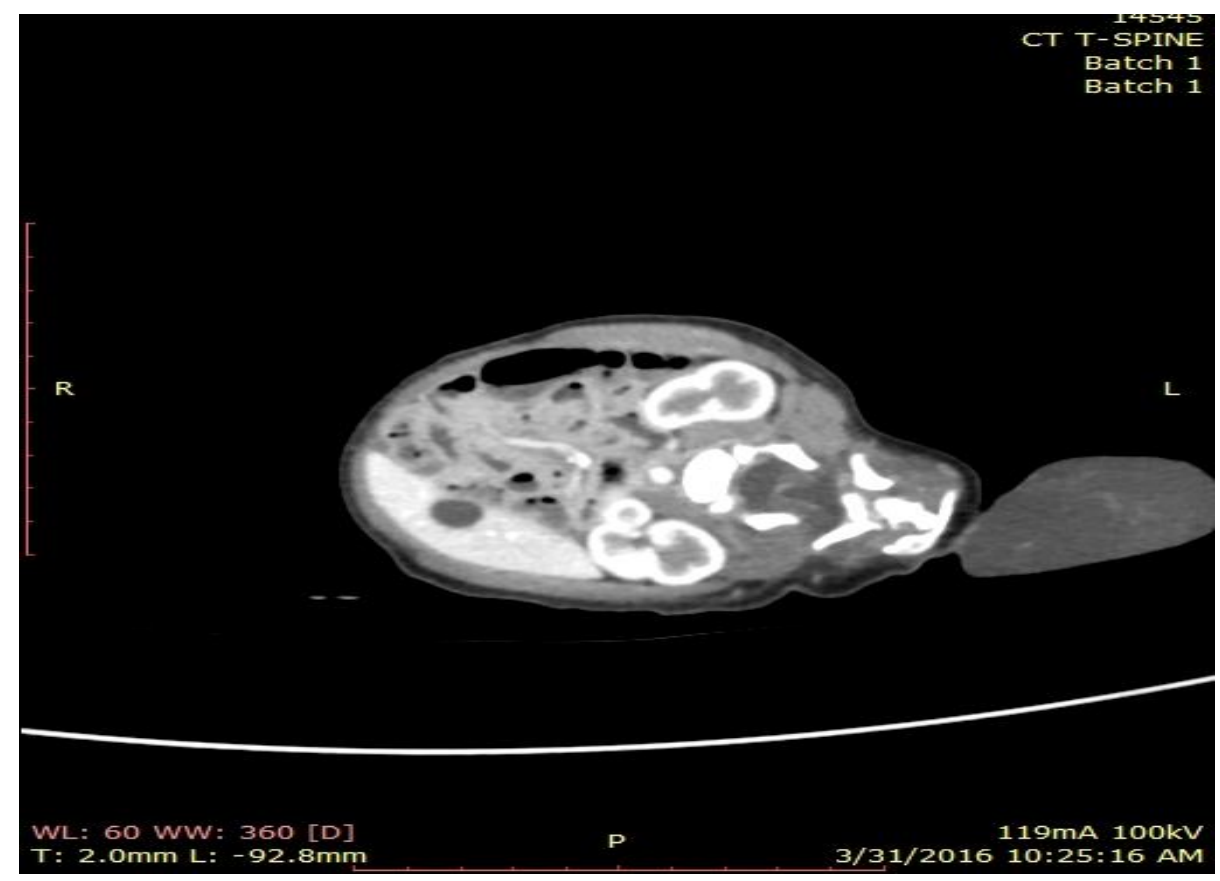

Figure 3. Axial CT image demonstrating the bony component of the mass suggesting rudimentary vertebral bones. 


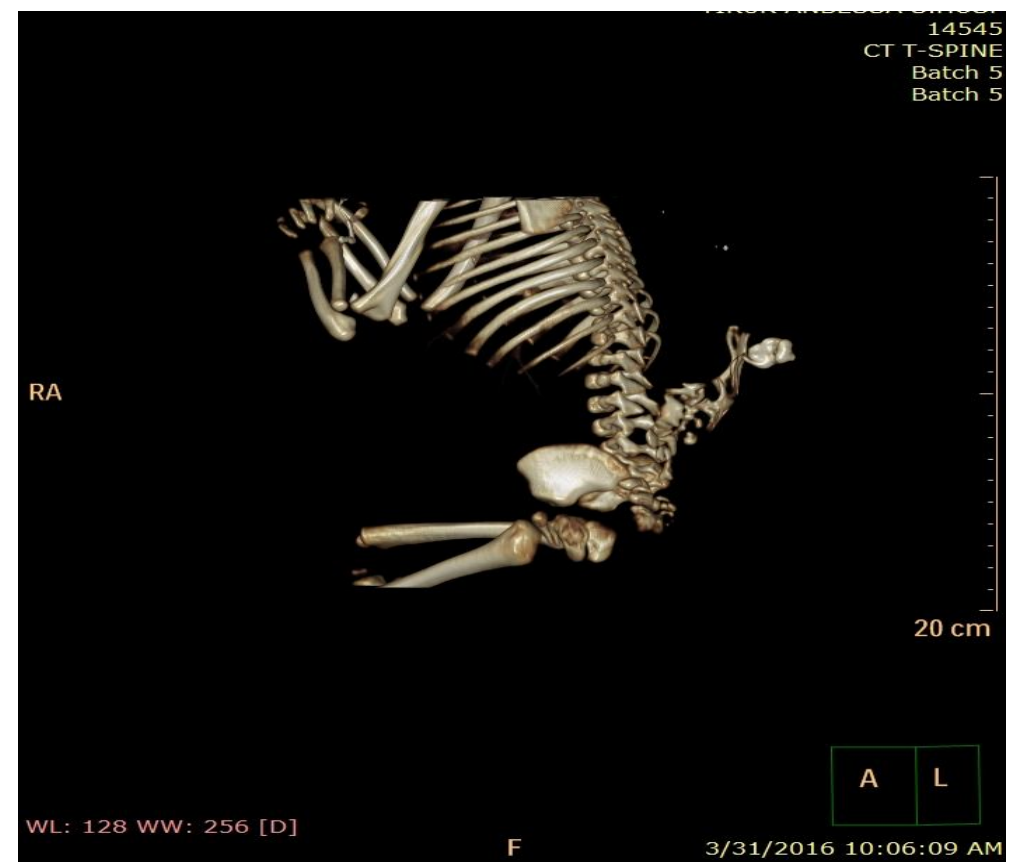

Figure 4. A volume-rendered CT image of the baby showing the full extent of the rudimentary bonearising from the lumbar spine.

rudimentary external genital. Sharma et al. (2012) reported two of three cases with spina bifida and hemivertebrae. Zhang et al. (2011) reported rachiphagus conjoined twinning in a seventeen year-old female with spina bifida, tethered cord, diplomyelia, scoliosis, and ventricular septal defect. In our case, the component of the conjoined twin that is attached to the autosite had no well-formed limb bone but rudimentary spinal components. No other anomalies in the autosite were picked. Resection of the mass with repair was done; surgery was uneventful and the neonate was discharged on the $4^{\text {th }}$ post operation day.

\section{CONCLUSION}

Although this is a rather rare occurrence, we believe that the local medical community will no doubt benefit from the information in terms of the role sectional imaging plays in the identification of such an anomaly by providing a detailed morphological study of the site and extent of the anomalous twinning for accurate surgical removal of the parasite and subsequent correction of defects in the autosite.

\section{ACKNOWLEDGEMENT}

We would like to forward our appreciation to the Department of Radiology, CHS, Addis Ababa University for being handy in the preparation of this case report.

We would like also to thank the family of this neonate for allowing us to publish the case and our colleagues in radiology and neurosurgery for their help in the realization of this case report.

\section{REFERENCES}

Aktar N, Karim S, Parveen T, Sayeeda S, Begum F, 2012. Variants of conjoined twins; two case reports. BSMMU J, 5(1): 65-68.

Fierling R, Däster C, Arlettaz MR, 2015. Heteropagus twins: a report of two cases. Swiss Society of Neonatology. pp 1-22.

Gopal K, S Kumar, Jaisawal P, Raghwendra KH, Jha SK, Prasad AK, Kumar AN, 2015. Intrahepatic fetus-in-fetu in adult male: A case report and review of the literature. Int J Adv Case Rep, 2(15): 963 966

Sanoussi S, Rachid S, Sani CM, Mahamane B, Addo G, 2010. Rachipagus: A report of two cases - thoracic and lumbar. J Surg Technique Case Rep, 2(1): 27-29.

Sharma A, Goyal A, Sharma S, 2012. Fetus in fetu: A rare case report. J Res Med Sci, 17: 491-494.

Singh SP, 2012. A rare form of heteropagus twinning managed in his preadolescent hood in a rural tertiary level medical institute. IJCRI, 3980: 31-33.

Solak A, Ergun S, Polat I, Şahin N, Genç B, 2012. A rare form of heteropagus twinning: Three-armed infant with spinal dysraphism. Case Rep Pediatr, 1-4.

Trainavicius K, Kazlauskas V, Gurskas P, 2013. Epigastric heteropagus conjoined twins. J Ped Surg Case Reports, 1: 114-117.

Zhang J, Duan H, Zhang Y, Yi Z, Bao S, 2011. Parasitic rachipagus conjoined twins with spina bifida, diplomyelia, scoliosis, tethered cord syndrome, and ventricular septal defect: A case report. Neuro Med Chir (Tokyo): 51: 736-739.

Citation: Solomon DZ, Fekadu N, Gorfu Y, 2018. Rachipagus parasitic twin in an Ethiopian neonate: A case report from the Horn of Africa. Int Res J Med Med Sci, 6(3): 56-59. 